\title{
Surface Processing by Polyatomic Cluster Ion Beams*
}

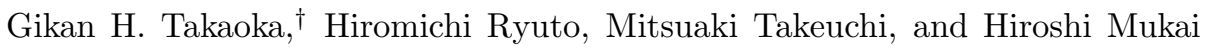 \\ Photonics and Electronics Science and Engineering Center, \\ Kyoto University, Katsura, Nishikyo-ku, Kyoto 615-8510, Japan \\ (Received 28 October 2010; Accepted 3 March 2011; Published 9 April 2011)
}

\begin{abstract}
We produced polyatomic clusters such as ethanol and water clusters by an adiabatic expansion phenomenon of vaporized material. The cluster ions were irradiated by changing the incident energy on various kinds of substrates such as mica, $\mathrm{Si}(100), \mathrm{SiO}_{2}$ and photo-resist substrates. AFM observation showed that irradiation trace with the diameter of approximately $20 \mathrm{~nm}$ was formed on mica substrates by ethanol cluster ion irradiation. Also, it showed that surface roughness of $\mathrm{Si}(100)$ substrates irradiated was less than $1 \mathrm{~nm}$, even though the surface was sputtered by ethanol and water cluster ion irradiation. Furthermore, RBS channeling measurement showed that the irradiation damage of $\mathrm{Si}(100)$ surfaces sputtered by ethanol and water cluster ions was smaller than that by the Ar monomer ion irradiation. With regards to sputtering and patterning, the sputtered depth of $\mathrm{Si}(100), \mathrm{SiO}_{2}$ and photo-resist surfaces by ethanol cluster ion irradiation increased with increase of the acceleration voltage. The sputtering yield of the $\mathrm{Si}(100)$ surface was a few hundreds times higher than that by Ar monomer ion irradiation at the same acceleration voltage. In addition, micro-patterning was performed on the $\mathrm{Si}(100)$ surface, and sharp-edged patterns with a line-width of $0.5 \mu \mathrm{m}$ to $3 \mu \mathrm{m}$ were achieved by ethanol cluster ion irradiation. [DOI: 10.1380/ejssnt.2011.168]

Keywords: Cluster; Ion bombardment; Ion-solid interactions; Sputtering; Mica; Silicon; Photo-resist film; SEM
\end{abstract}

\section{INTRODUCTION}

The cluster ion beam process, which is one of the basic technologies in nanostructure fabrications as well as surface analyses at an atomic level, has attracted much interest $[1-6]$. We have succeeded in producing polyatomic clusters such as ethanol and water clusters by an adiabatic expansion phenomenon of vaporized material [7, 8], even if helium gas is not added to decrease the temperature of vapors. In a polyatomic molecule, various kinds of radicals such as alkyl and hydroxyl radicals are available, and they can be used effectively in the surface processing. In addition, irradiation effects of cluster ions such as high density, multiple-collision and low energy irradiation effects can provide unique properties. For example, the high density irradiation effect can increase the surface temperature of impact region $[9,10]$, which is effective to enhance the chemical reaction on the surface. Also, multiple collision effect can enhance the lateral motion of constituent atoms or molecules on the surface [11, 12], which is effective to enhance a flat surface formation by lateral sputtering effect. These effects have not been obtained by conventional ion beam technique.

Impact of polyatomic cluster ions on solid surface represents various interactions with surface atoms depending on incident energy and cluster size. At low incident energy corresponding to thermal energy, the polyatomic cluster might be broken up into molecules after impact, and the migration of constituent molecules might increase with the increase of incident energy. When the incident energy becomes higher, the dissociation of a constituent molecule might occur, and the surface modification by various kinds of radicals produced might be enhanced. At higher incident energies, the dissociation of a molecule proceeds, and fragment atoms might be implanted into

*This paper was presented at the 6th International Workshop on Nano-scale Spectroscopy and Nanotechnology (NSS-6), Kobe University Centennial Hall, Kobe, Japan, 25-29 October, 2010.

†Corresponding author: gtakaoka@kuee.kyoto-u.ac.jp the surface region. With regards to high density irradiation and multiple collisions by polyatomic cluster ions, the incident energy per molecule, which is related to the cluster size and the incident energy, is an important factor in the investigation of interactions with surface atoms. In this article, on the basis of the irradiation effects of polyatomic cluster ions on solid surfaces, high-rate sputtering by ethanol cluster ion irradiation is discussed, and micropatterning is described as an engineering application of polyatomic cluster ion beams.

\section{EXPERIMENTAL PROCEDURE}

The details of experimental apparatus were described elsewhere [13]. Liquid material, such as ethanol and water selected as polyatomic-molecular material, was introduced into the cluster source, and it was heated up to $150^{\circ} \mathrm{C}$ by a wire heater attached around the source. The vapors of liquid materials were ejected through a nozzle into a vacuum region. When the vapor pressure was higher than $0.1 \mathrm{MPa}$, the cluster was produced by adiabatic expansion phenomena. The size of clusters was measured by the time-of-flight (TOF) method, and it was assumed that the cluster ion was a singly charged particle. The cluster size was distributed between a few hundreds and a few tens of thousands. The average size (peak size) was approximately 1,500 molecules for ethanol cluster and approximately 4,000 molecules for water cluster, respectively. The clusters produced passed through a collimator and entered an ionizer. In the ionizer, neutral clusters were ionized by an electron bombardment method. The electron voltage for ionization $\left(V_{\mathrm{e}}\right)$ was adjusted between $0 \mathrm{~V}$ and $300 \mathrm{~V}$, and the electron current for ionization $\left(I_{\mathrm{e}}\right)$ was adjusted between $0 \mathrm{~mA}$ and $250 \mathrm{~mA}$. In order to remove the monomer ions and control the minimum size of the cluster ions, a retarding potential method was used. The minimum size of cluster ions was adjusted between 300 molecules and 1,000 molecules by controlling the retarding voltage. The size-separated cluster ions were accelerated toward a substrate, which was set on a substrate holder. The acceleration voltage $\left(V_{\mathrm{a}}\right)$ 


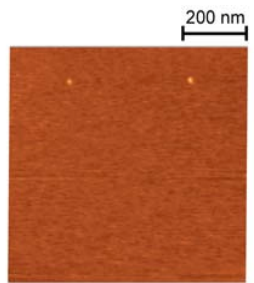

$20 \mathrm{~nm}$

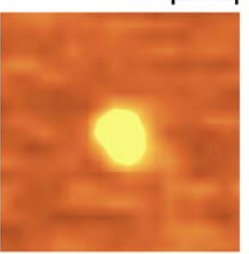

(a) $\mathrm{Va}=3 \mathrm{kV}$

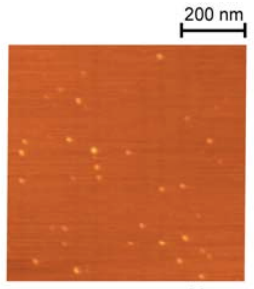

$20 \mathrm{~nm}$

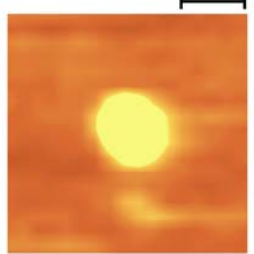

(b) $\mathrm{Va}=6 \mathrm{kV}$

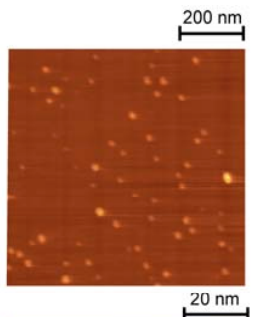

$20 \mathrm{~nm}$

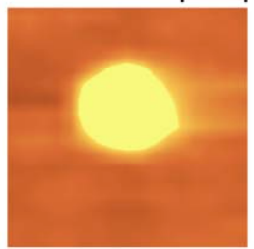

(c) $\mathrm{Va}=9 \mathrm{kV}$
FIG. 1: AFM images of mica substrates irradiated by ethanol cluster ions at acceleration voltages of (a) $3 \mathrm{kV}$, (b) $6 \mathrm{kV}$ and (c) $9 \mathrm{kV}$, respectively. The ion dose was $1.0 \times 10^{12} \mathrm{ions} / \mathrm{cm}^{2}$.

was adjusted between $0 \mathrm{kV}$ and $10 \mathrm{kV}$. The substrates used were mica, $\mathrm{Si}(100), \mathrm{SiO}_{2}$ and photo-resist films. The photo-resist films were prepared on $\mathrm{Si}(100)$ substrates by a spin coating method, and the film thickness was approximately $1.0 \mu \mathrm{m}$. The substrate surfaces irradiated by cluster ions were measured by using an atomic force microscope (AFM). The irradiation damage was measured by the Rutherford backscattering (RBS) method, and the number of displacement atoms for the $\mathrm{Si}(100)$ surfaces irradiated was estimated.

Mask patterns such as line patterns were commercially available, and they were made on a Si (100) substrate by Yamanaka Semiconductor Co. Ltd. The line width was in the range of $0.5 \mu \mathrm{m}$ to $3 \mu \mathrm{m}$. The thickness of the photoresist film coated on the mask was $1.0 \mu \mathrm{m}$. Ethanol cluster ions were irradiated on the mask-patterned surface of $\mathrm{Si}$ (100) substrate. The irradiated surface with and without the photo-resist mask was observed by the scanning electron microscope (SEM).

\section{RESULTS AND DISCUSSION}

\section{A. Irradiation effects of cluster ions on solid surfaces}

The impact of polyatomic cluster ions on solid surfaces represents unique features such as high density irradiation, multiple collisions and low energy irradiation. Figure 1 shows AFM images of mica $\left(\mathrm{KFe}_{3} \mathrm{AlSi}_{3} \mathrm{O}_{10}(\mathrm{OH})_{2}\right)$ substrates irradiated by ethanol cluster ions at acceleration voltages of (a) $3 \mathrm{kV}$, (b) $6 \mathrm{kV}$ and (c) $9 \mathrm{kV}$, respectively. The upper part represents the mages with large area, and the lower part with small area. The cluster size used was larger than 300 molecules per cluster. The ion dose was $1.0 \times 10^{12}$ ions $/ \mathrm{cm}^{2}$, and the number of incident cluster ions in the area of $1 \mu \mathrm{m} \times 1 \mu \mathrm{m}$ was about $10^{4}$. As shown by bright dots in the figure, a few traces with diameter of approximately $13 \mathrm{~nm}$ is observed in the image at the acceleration voltage of $3 \mathrm{kV}$. The diameter of the trace increases with increase of the acceleration voltage, and it is approximately $16 \mathrm{~nm}$ and $19 \mathrm{~nm}$ at the acceleration voltage of $6 \mathrm{kV}$ and $9 \mathrm{kV}$, respectively. At all incident energies, the trace of cluster ion impact is shaped in a rough circle. There is no hole in the center of the trace. With regards to the acceleration voltage dependence, the diameter of the trace changes according to the one third power of the acceleration voltage. This indicates that three-dimensional dissipation of incident energy occurs in the trace formation. In addition, the high density of incident energy spreads away into the substrate, and the temperature of the impact region increases. As a result, the chemical reaction, such as $\mathrm{K}+\mathrm{OH}$, on the surface of mica substrate enhances, and the trace with a diameter of approximately $20 \mathrm{~nm}$, which is larger than a diameter of a cluster ion, is formed.

Furthermore, as shown in the figure, the number of the trace increases with increase of the acceleration voltage. However, the number at the acceleration voltage of $3 \mathrm{kV}$ is much smaller than that calculated from the ion dose by assuming that a trace corresponds to an impact point of a cluster ion. This suggests that the number of cluster ions with the incident energy larger than the threshold energy for the trace formation is a few. Furthermore, the threshold energy at the acceleration voltage of $3 \mathrm{kV}$ is estimated to be approximately $10 \mathrm{eV}$ per molecule, because the minimum size of cluster ions used is 300 molecules per cluster. The energy of $10 \mathrm{eV}$ per molecule is relatively low to occur physical sputtering of mica surface, and it is related to the threshold energy for dissociation of an ethanol molecule or for chemical erosion of the mica surface such as $\mathrm{KOH}$ formation. While the $\mathrm{KOH}$ formation proceeds on the mica surface, the surface is sputtered by the irradiation of following-up cluster ions. Also, the chemical modification of mica surface is enhanced with increase of the number of the cluster ions which have the energy larger than $10 \mathrm{eV}$ per molecule. The number of such the cluster ions increases with increase of the acceleration voltage, which results in an increase of the trace. In addition, the AFM analysis showed that the trace exhibited the bell shape without a hole, and the height of the trace at the acceleration voltage of $3 \mathrm{kV}, 6 \mathrm{kV}$ and $9 \mathrm{kV}$ was $0.4 \mathrm{~nm}, 0.8 \mathrm{~nm}$ and $1.4 \mathrm{~nm}$, respectively. This indicates that the bell-shaped trace with a small height is formed by the ethanol cluster ion impact on the mica substrate.

Figure 2 shows AFM images of $\mathrm{Si}(100)$ substrates irradiated by ethanol and water cluster ions. The acceleration voltage was $6 \mathrm{kV}$, and the ion dose was $1.0 \times 10^{16}$ ions $/ \mathrm{cm}^{2}$. The cluster size used was larger than 300 molecules per cluster. An AFM image for the unirradiated substrate is also shown, and the surface roughness $\left(R_{a}\right)$ is $0.18 \mathrm{~nm}$. On the other hand, the sputtered Si surfaces become rough, and the surface roughness $\left(R_{a}\right)$ is $0.93 \mathrm{~nm}$ for ethanol cluster ion irradiation and $0.78 \mathrm{~nm}$ for water cluster ion irradiation, respectively. Smooth surface with a roughness less than $1 \mathrm{~nm}$ is obtained even after sputtering at a sputtered depth of $243 \mathrm{~nm}$ and $15 \mathrm{~nm}$ by ethanol and water cluster ion irradiation, respectively. This is partially due to the lateral sputtering effect by the cluster ion irradiation, in which the migration of the molecule on the surface increases with increase of the incident energy.

Figure 3 shows the number of displacement atoms for the $\mathrm{Si}(100)$ surfaces irradiated at different acceleration 


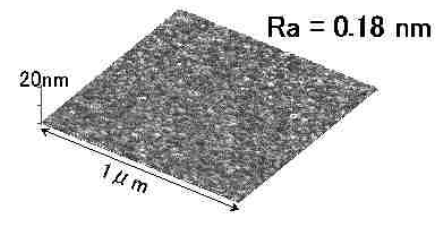

(a)Unirradiated

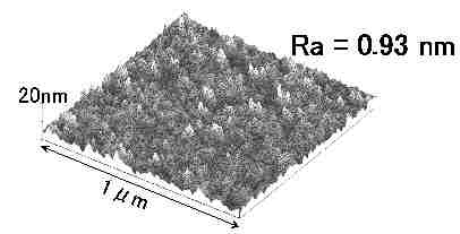

(b)Ethanol cluster ion $\mathrm{Va}=6 \mathrm{kV} 、$ Dose $=1.0 \times 10^{16} \mathrm{ions} / \mathrm{cm}^{2}$

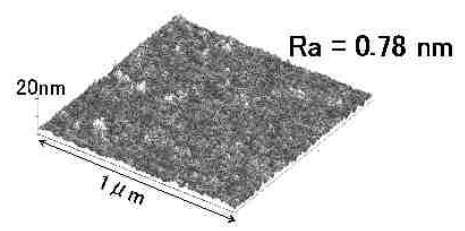

(c) $\mathrm{H}_{2} \mathrm{O}$ cluster ion

$\mathrm{Va}=6 \mathrm{kV}$, Dose $=1.0 \times 10^{16} \mathrm{ions} / \mathrm{cm}^{2}$

FIG. 2: AFM images of $\mathrm{Si}(100)$ substrates irradiated by ethanol and water cluster ions. The acceleration voltage was $6 \mathrm{kV}$, and the ion dose was $1.0 \times 10^{16}$ ions $/ \mathrm{cm}^{2}$.

voltages by ethanol and water cluster ions. To be compared with the cluster ions, argon (Ar) monomer ions were irradiated on the substrate. The ion dose was $1.0 \times 10^{15}$ ions $/ \mathrm{cm}^{2}$, and the cluster size used was larger than 300 molecules per cluster. As shown in the figure, the number of displacement atoms for the ethanol and water cluster ion irradiation is less than that for the Ar monomer ion irradiation at the same acceleration voltage. With regard to the cluster ion irradiation, the incident energy of a molecule is the accelerating energy divided by the cluster size, and it is very low. Therefore, the damage induced by the cluster ion irradiation is less than that by Ar monomer ion irradiation. In addition, at an acceleration voltage of $1 \mathrm{kV}$, the number of displacement atoms by the ethanol cluster ion irradiation is the same as that of the unirradiated surface. Because the incident energy of an ethanol molecule is less than a few eV per molecule, the damage-free surface is obtained by extremely low energy irradiation effect of the ethanol cluster ions.

Figure 4 shows the retarding voltage dependence of irradiation damage on the $\mathrm{Si}(100)$ surfaces by the ethanol cluster ion beams. The acceleration voltage was $6 \mathrm{kV}$, and the ion dose was kept at $1.0 \times 10^{15}$ ions $/ \mathrm{cm}^{2}$. As shown in the figure, the number of displacement atoms decreases with increase of the retarding voltage. This indicates that the irradiation damage is closely related to the minimum size of cluster ion as well as the incident energy. However, it is noted that the number of displacement atoms at higher retarding voltages does not become zero. This is considered to be due to the existence of ethanol molecules,

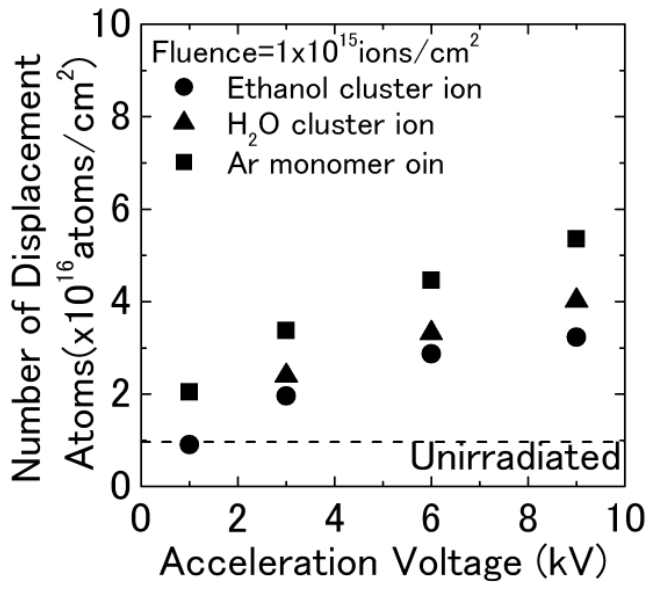

FIG. 3: Number of displacement atoms for the $\mathrm{Si}(100)$ surfaces irradiated at different acceleration voltages by ethanol and water cluster ions and by Ar monomer ion. The ion dose was $1.0 \times 10^{15}$ ions $/ \mathrm{cm}^{2}$, and the retarding voltages was $27 \mathrm{~V}$.

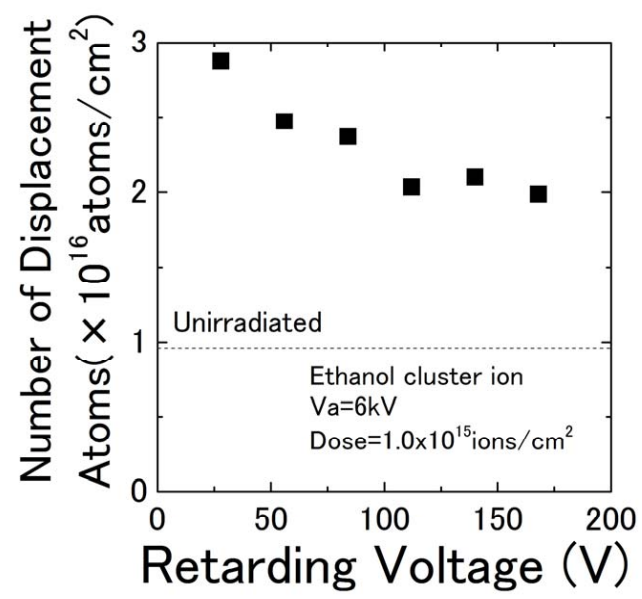

FIG. 4: Number of displacement atoms for the Si(100) surfaces irradiated at different retarding voltages by ethanol cluster ions. The acceleration voltage was $6 \mathrm{kV}$, and the ion dose was $1.0 \times 10^{15}$ ions $/ \mathrm{cm}^{2}$.

which might be deposited and remain on the Si surface. Another reason, which is now under consideration, is that the volatile materials ejected from the Si surface might be re-deposited on the surface. According to the XPS measurement, $\mathrm{C} 1 s$ and $\mathrm{O} 1 s$ peaks for the irradiated Si surface disappeared after etching at a depth of $0.5 \mathrm{~nm}$. This indicated that compound materials consisting of carbon, oxygen and hydrogen remained on the reactive Si-surface just after ethanol cluster ion irradiation. It is considered from the XPS measurment that the materials might be present on the Si surface due to the formation of ethanol molecule layers and/or volatile Si-compounds.

\section{B. Sputtering and micro-patterning}

Figure 5 shows the dependence of sputtered depth for $\mathrm{Si}(100)$ substrates, $\mathrm{SiO}_{2}$ and photo-resist films on the acceleration voltage. The ion dose was $1.0 \times 10^{16} \mathrm{ions} / \mathrm{cm}^{2}$, 


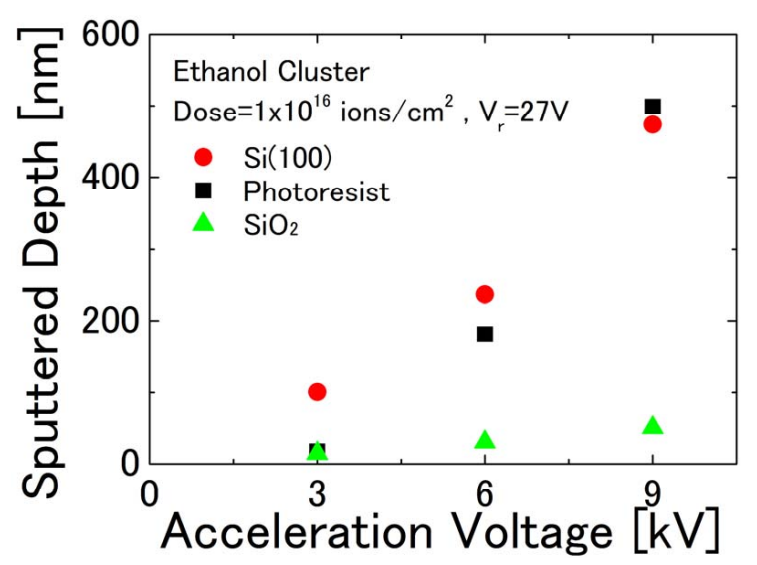

FIG. 5: Dependence of sputtered depth for $\mathrm{Si}(100)$ substrates, $\mathrm{SiO}_{2}$ and photo-resist films on the acceleration voltage. The ion dose was $1.0 \times 10^{16}$ ions $/ \mathrm{cm}^{2}$.

and the cluster size used was larger than 300 molecules per cluster. As shown in the figure, the sputtered depth increases with increase of the acceleration voltage. When the acceleration voltage is $9 \mathrm{kV}$, the sputtered depth is $475 \mathrm{~nm}$ for $\mathrm{Si}, 47.2 \mathrm{~nm}$ for $\mathrm{SiO}_{2}$ and $498 \mathrm{~nm}$ for photoresist, respectively. The ratio of the sputtered depth for $\mathrm{Si}$ to $\mathrm{SiO}_{2}$ is approximately 10 , and the ratio of the sputtered depth for Si to photo-resist is almost unity. Taking account of the sputtered depth and the ion dose, the sputtering yield can be calculated by estimating the density of Si such as $2.42 \mathrm{~g} / \mathrm{cm}^{3}$. The sputtering yield of $\mathrm{Si}$ at an acceleration voltage of $9 \mathrm{kV}$ is 246 atoms per ion, which is a few hundreds times larger than that by Ar ion beam sputtering. This is ascribed to the chemical sputtering of the Si surfaces by the ethanol cluster ion beams. After impact of the ethanol cluster ions on the Si surface, hydrogen atoms and alkyl radicals are produced through the dissociation of the ethanol molecule. They react with the Si surface atoms as follows;

$$
\begin{aligned}
\mathrm{Si}+m \mathrm{H} & \rightarrow \mathrm{SiH}_{m} \uparrow \\
\mathrm{Si}+n \mathrm{CH}_{3} & \rightarrow \mathrm{Si}\left(\mathrm{CH}_{3}\right)_{n} \uparrow
\end{aligned}
$$

In order to study the dissociation process of an ethanol molecule on a $\mathrm{Si}(100)$ surface, the First-Principles calculation was performed using the computer software named Materials Studio (Accelrys Co.). The bonding energy for $\mathrm{Si}-\mathrm{Si}$ bond was assumed to be $2.3 \mathrm{eV}$. Furthermore, the bonding energy of other bonds such as $\mathrm{C}-\mathrm{H}$ bond, $\mathrm{C}-\mathrm{C}$ bond, $\mathrm{C}-\mathrm{O}$ bond and $\mathrm{O}-\mathrm{H}$ bond in an ethanol molecule was fixed at $4.3 \mathrm{eV}, 3.6 \mathrm{eV}, 3.7 \mathrm{eV}$ and $4.8 \mathrm{eV}$, respectively. According to the computer simulation, the ethanol molecule started to be dissociated into $\mathrm{C}_{2} \mathrm{H}_{5} \mathrm{O}$ and $\mathrm{H}$ radicals at incident energy of approximately $12 \mathrm{eV}$, and the chemical erosion and sputtering occurred on the Si surface. Furthermore, it was found from the XPS measurement for sputtered materials that silicon hydride and silicon hydro-carbide materials as a volatile compound described in Eqs. (1) and (2) were ejected from the Si substrate surface after the ethanol cluster ion irradiation [14].

As an engineering application of high-rate sputtering by the ethanol cluster ion beams, micro-patterning was performed on the $\mathrm{Si}(100)$ surface with a photo-resist mask.

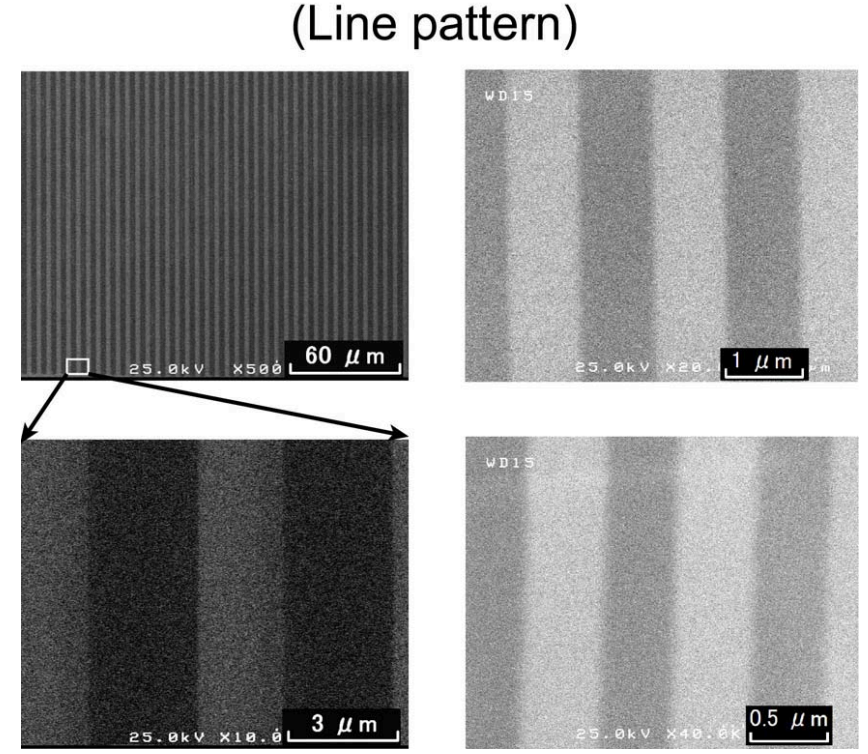

FIG. 6: SEM images for the line patterns demonstrated with ethanol cluster ion beams. The acceleration voltage was $9 \mathrm{kV}$, and the ion dose was $5.0 \times 10^{15}$ ions $/ \mathrm{cm}^{2}$.

Figure 6 shows the line patterns demonstrated with the ethanol cluster ion beams. The acceleration voltage was $9 \mathrm{kV}$, and the ion dose was $5.0 \times 10^{15}$ ions $/ \mathrm{cm}^{2}$. After the ethanol cluster ion irradiation, the photo-resist film on the $\mathrm{Si}(100)$ surface was removed by acetone rinsing. As shown in the figure, the edge with a line width of $3 \mu \mathrm{m}, 1 \mu \mathrm{m}$ and $0.5 \mu \mathrm{m}$ is straight, and the micro-pattern is clearly made by the ethanol cluster ion irradiation. Also, the sputtered depth is approximately $220 \mathrm{~nm}$. However, the side wall etched is not perpendicular to the bottom surface, which is not shown in the figure. This might be ascribed by re-deposition of the $\mathrm{Si}$ atoms sputtered from the bottom plane onto the side wall or by bending of ion beam line due to the charging-up on the photo-resist mask.

\section{CONCLUSION}

In order to investigate the interactions of polyatomic cluster ions with solid surfaces, the ethanol and water cluster ions were irradiated by changing the incident energy on various kinds of substrates such as mica, $\mathrm{Si}(100), \mathrm{SiO}_{2}$ and photo-resist substrates. AFM observation showed that irradiation trace with the diameter of approximately $20 \mathrm{~nm}$ was formed on mica substrates by ethanol cluster ion irradiation. The threshold energy for the trace formation was estimated to be approximately $10 \mathrm{eV}$ per molecule. Also, it showed that surface roughness of Si substrates irradiated was less than $1 \mathrm{~nm}$, even though the surface was sputtered by ethanol and water cluster ion irradiation. The smooth surface formation was ascribed to the lateral sputtering effect by the cluster ion irradiation. Furthermore, RBS channeling measurement showed that the irradiation damage of $\operatorname{Si}(100)$ surfaces sputtered by ethanol and water cluster ions was smaller than that by the Ar monomer ion irradiation. This was due to the low energy irradiation effect by the cluster ion 
beams.

With regards to sputtering and patterning, the sputtered depth of $\mathrm{Si}(100), \mathrm{SiO}_{2}$ and photo-resist surfaces by ethanol cluster ion irradiation increased with increase of the acceleration voltage. The sputtering yield of the $\mathrm{Si}(100)$ surface was a few hundreds times higher than that by $\mathrm{Ar}$ monomer ion irradiation at the same acceleration voltage. The high-rate sputtering of $\mathrm{Si}(100)$ surfaces was due to the chemical sputtering by the ethanol cluster ion irradiation. In addition, micro-patterning was performed on the $\mathrm{Si}(100)$ surface, and sharp-edged patterns with a line-width of $0.5 \mu \mathrm{m}$ to $3 \mu \mathrm{m}$ were achieved by ethanol cluster ion irradiation.

\section{Acknowledgments}

The authors are grateful to the Quantum Science and Engineering Center of Kyoto University for the RBS measurement. Furthermore, a part of the work such as SEM observation was supported by "Nanotechnology Support Project" of the Ministry of Education, Culture, Sports, Science and Technology (MEXT), Japan.
[1] Proc. 17th Int. Conf. on Ion Implant. Technol. IIT2008 (AIP Conf. Proc., Vol.1066, 2008), Chap. Session: Molecular and Cluster Ion Beams, p. 387.

[2] A. Moudens, R. Georges, M. Goubet, J. Makarewicz, S. E. Lokshtanov, and A. A. Vigasin, J. Chem. Phys. 131, 204312 (2009).

[3] C. Xirouchaki and R. E. Palmer, Vacuum 66, 167 (2002).

[4] J. H. Song, D. K. Choi, and W. K. Choi, Nucl. Instrum. Methods Phys. Res. B 196, 268 (2002).

[5] K. Iltgen, C. Bendel, A. Benninghoven, and E. Niehuis, J. Vac. Sci. Technol. A 15, 460 (1997).

[6] H. Harberland, M. Karrais, M. Mall, and Y. Thurner, J. Vac. Sci. Technol. A 10, 3266 (1992).

[7] G. H. Takaoka, H. Noguchi, K. Nakayama, and M. Kawashita, e-J. Surf. Sci. Nanotech. 4, 473 (2006).

[8] G. H. Takaoka and M. Kawashita, Synth. Reactiv. in In- organic Metal-Organic and Nano-Metal Chem. 38, 111 (2008).

[9] Z. Insepov and I. Yamada, Surf. Rev. Lett. 3, 1023 (1996).

[10] Z. Insepov and I. Yamada, Nucl. Instrum. Methods Phys. Res. B 121, 44 (1997).

[11] H. Hsieh, R. S. Averback, H. Sellers, and C. P. Flynn, Phys. Rev. B 45, 4417 (1992).

[12] H. Yasumatsu and T. Kondow, Rep. Prog. Phys. 66, 1783 (2003).

[13] G. H. Takaoka, Chemical Reactions on Surfaces Ed. by J. I. Duncan and A. B. Klein (Nova Science Publishers, Inc, 2008), Chap. 3.

[14] H. Ryuto, R. Ozaki, H. Mukai, and G.H. Takaoka, Vacuum 84, 1419 (2010). 